Historic, Archive Document

Do not assume content reflects current scientific knowledge, policies, or practices. 
$$
\text { , }
$$ 
aSF995

.6
2011

iited States Department of Agriculture

imal and Plant Health Inspection Service

ogram Aid No. 2079

Important Information for Backyard Poultry Owners

\section{Protect Your Birds From Avian Influenza (Bird Flu)}

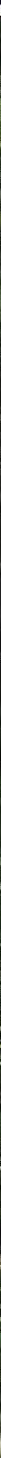




\section{How Does Bird Flu Spread?}

\section{HPAI spreads quickly by direct,}

bird-to-bird contact. The disease can

also spread indirectly, for example,

when birds come in contact with

contaminated surfaces or materials.

Migratory waterfowl (i.e., wild ducks and geese), smuggled poultry and poultry products, and the movement of poultry, poultry equipment, and people are potential sources for introducing the disease to domestic birds. The bird flu virus can travel on manure, egg flats, crates, other farming materials/equipment, and people who have picked up the virus on their clothing, shoes, or hands.

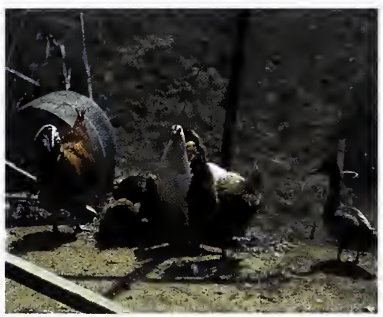

USDA file photo Allowing backyard flocks to come in contact with wild birds could put them at risk for infectious poultry diseases such as HPAI.

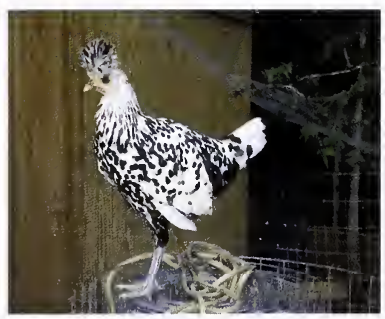

Deanna Stinnet

Don't share equipment, tools, or poultry supplies with neighbors or other bird owners. If you must, disinfect these items before bringing them home.

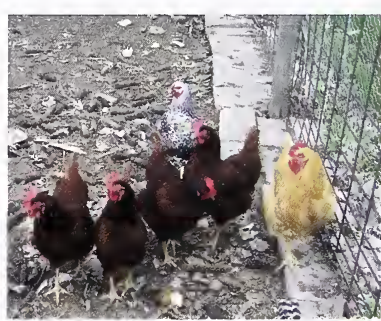

Polly Berkenstock

Fencing your bird area can help keep your flock safe from predators and from contact with other birds that could spread disease.

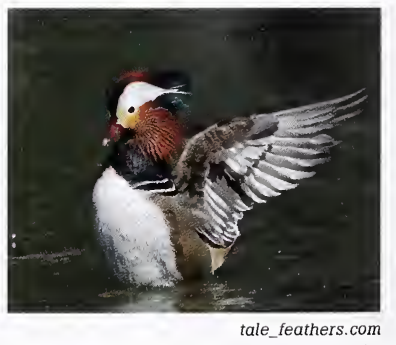

Migratory waterfowl could potentially introduce HPAI to your birds. So be sure they don't share a water source with your birds, and keep your birds' food protected. 


\section{How USDA Works To Keep HPAI Out of the Country}

HPAI is a threat to U.S. poultry. The

United States is the world's largest

producer and exporter of poultry meat

and the second largest egg producer.

Total U.S. poultry production is valued at nearly $\$ 32$ billion annually. A major outbreak of HPAI would be costly to the poultry industry, consumers, and taxpayers and could harm backyard flocks as well.

To protect the U.S. poultry population, USDA quarantines and tests live birds imported into the United States to ensure that they do not have any foreign animal diseases such as HPAI. USDA also maintains trade restrictions on poultry and poultry products from countries and/or regions where HPAI has been detected in commercial or traditionally raised poultry.

Surveillance is another important part of USDA's efforts to protect the health of U.S. flocks. USDA monitors for illegally smuggled poultry and poultry products through an anti-smuggling program in coordination with the U.S. Department of Homeland Security's Customs and Border Protection. In addition, USDA works with a nationwide network of Federal and State partners, university personnel, USDAaccredited veterinarians, and industry members to monitor for HPAI in key areas of the country's bird population. These areas include live bird markets, commercial flocks, backyard flocks, and migratory birds. 


\section{What Is Bird Flu?}

\section{Avian influenza (AI), or "bird flu," is}

a virus that infects domestic poultry,

such as chickens, turkeys, quail,

and geese, and wild birds such as

shorebirds and waterfowl.

AI viruses are divided into two groups-highly pathogenic (HPAI) and low pathogenic (LPAI)-based on the ability of the virus to produce disease and the severity of illness it can cause. HPAI spreads rapidly and has a high death rate in birds. LPAI causes only minor illness and occurs naturally in migratory waterfowl. The concern is that some LPAI virus strains are capable of mutating into HPAI viruses.

HPAI viruses are considered exotic or foreign to the United States because they do not occur naturally here. HPAI has been detected and eradicated by the U.S. Department of Agriculture (USDA) three times: in 1924, 1983, and 2004. The 1983 outbreak resulted in the deaths of about 17 million chickens, turkeys, and guinea fowl in Pennsylvania and Virginia. Managing this outbreak cost nearly \$65 million and caused retail egg prices to increase by more than 30 percent. 


\section{What Are the Signs of Bird Flu?}

\section{HPAI can strike quickly and spread}

rapidly without any warning. When infected birds do show signs, here's what to look for:

- Lack of energy and appetite

- Decreased egg production and/or soft-shelled or misshapen eggs

- Swelling of the head, eyelids, comb, wattles, and hocks

- Purple discoloration of the wattles, combs, and legs

- Runny nose, coughing, sneezing

- Stumbling or falling down

- Diarrhea

- Sudden death without any clinical signs

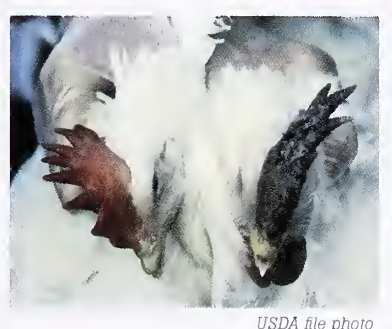

Purple discoloration of the comb could indicate HPAI.

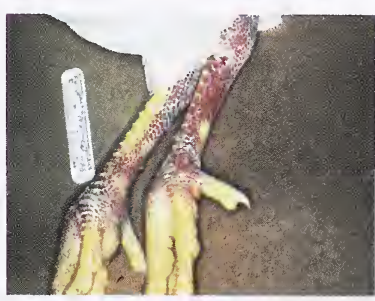

USDA file ph

Hemorrhaging of the skin and legs is just one of the signs birds might exhibit when infected with the HPAI virus.

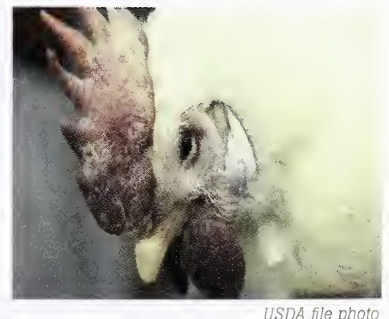

Birds affected by HPAI could show swelling of the head, wattles, combs, and face.

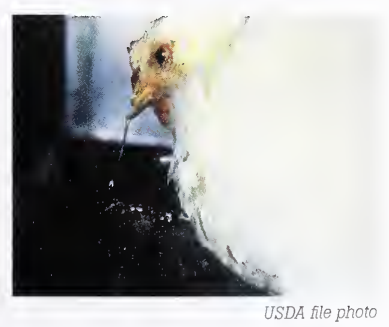

Nasal discharge (a runny nose) can be a sign of HPAI. 
Biosecurity For Birds is an outreach and education campaign to raise awareness among backyard poultry owners about the steps they can take to prevent AI and other infectious poultry diseases and what to do if they suspect a disease outbreak.

\section{More Information}

For information on keeping your birds healthy, visit USDA's Biosecurity For Birds Web site: http://healthybirds.aphis.usda.gov

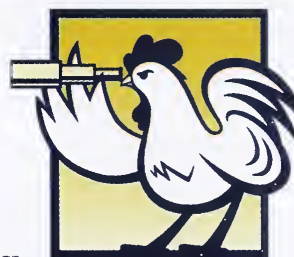

BIOSECURITY FOR BIRDS

For information about HPAI, contact:

USDA/APHIS/Veterinary Services

National Center for Animal Health

Emergency Management

4700 River Road, Unit 41

Riverdale, MD 20737-1231

Phone: (301) 734-8073

Fax: (301) 734-7817

The U.S. Department of Agriculture (USDA) prohibits discrimination in all its programs and activities on the basis of race, color, national origin, age, disability, and where applicable, sex, marital status, familial status, parental status, religion, sexual orientation, genetic information, political beliefs, reprisal, or because all or part of an individual's income is derived from any public assistance program. (Not all prohibited bases apply to all programs.) Persons with disabilities who require alternative means for communication of program information (Braille, large print, audiotape, etc.) should contact USDA's TARGET Center at (202) 720-2600

(voice and TDD). To file a complaint of discrimination, write to USDA, Director,

Office of Civil Rights, 1400 Independence Avenue, S.W., Washington, D.C

20250-9410, or call (800) 795-3272 (voice) or (202) 720-6382 (TDD).

USDA is an equal opportunity provider and employer. 